\title{
The opportunity costs of informal care: does gender matter?
}

\author{
Fiona Carmichael $^{\mathrm{a}, *}$, Susan Charles ${ }^{\mathrm{b}}$ \\ ${ }^{a}$ School of Accounting, Economics and Management Science, University of Salford, Salford M5 4WT, UK \\ ${ }^{\mathrm{b}}$ Department of Business and Management, University of Wales, Cledwyn Building, Penglais, \\ Aberystwyth, Ceredigion, Wales SY23 3DD, UK
}

Received 24 March 2000; accepted 28 March 2003

\begin{abstract}
In this paper, we investigate the costs borne by both male and female carers in terms of their forgone formal employment opportunities. Traditionally, informal care was supplied by women but nowadays women are not only more likely to work, but also likely to be significant contributors to family finances. For women, this implies that the size of any forgone earnings cost of informal care is increasing. At the same time, population ageing is making for increasing numbers requiring care. From a policy perspective it is therefore helpful to consider a less traditional but nevertheless important source of informal care, men. We find that both male and female carers bear indirect costs in that they are less likely to be in paid work than otherwise similar non-carers and when they are in paid work they earn significantly less. However, we find that the motivation for lower employment participation is not the same for men as it is for women.

(C) 2003 Elsevier Science B.V. All rights reserved.
\end{abstract}

JEL classification: $\mathrm{H} 2 ; \mathrm{J} 21 ; \mathrm{J} 22$

Keywords: Labour supply; Informal care; Community care; Wage determination

\section{Introduction}

A key objective of the social services modernisation programme ${ }^{1}$ launched by the UK government in 1998 is to help people to live independently. Central to this objective is

\footnotetext{
Material from the General Household Survey, made available through the Office of National Statistics and the ESRC Data Archive, has been used with permission of the Controller of HM Stationery Office.

${ }^{*}$ Corresponding author. Tel.: +44-161-2953001; fax: +44-161-2952130.

E-mail address: f.carmichael@salford.ac.uk (F. Carmichael).

${ }^{1}$ Department of Health (1998).
} 
continued support for the policy of caring for the elderly infirm and chronic sick in the community. ${ }^{2}$ Furthermore, government policy makers acknowledge that people generally want to live in their own homes if they can, and that within the community informal carers are the most important providers of social care. ${ }^{3}$ However, they also concede that "the care system does not adequately recognise the enormous contribution that informal carers make to maintain the independence of people with care needs" (Department of Health, 1998, para 2.10). In order to address this problem the government has included support for carers as one of the key elements in its action plan for modernising social services 4 and developed a national strategy for carers (Department of Health, 1999). But in order to develop appropriate support packages it is important to identify who is caring and discover how informal care responsibilities impact on their lives. With respect to the latter, a key element is the quantification of the opportunity costs that arise because of the constraints imposed on carers' labour supply by caring commitments. ${ }^{5}$ With respect to the question of identification the supply of informal care has traditionally been regarded as a female activity. However, successive General Household Surveys (GHS) ${ }^{6}$ have revealed that such activities are surprisingly common amongst men. This result is of some policy interest during a period when population ageing is making for ever increasing numbers needing care and labour market opportunities for women are expanding. The combination of these two factors raises doubts about women's continuing willingness to meet such needs on the required scale. Men are a potential alternative source of supply but, perhaps even more so than for their female counterparts, there may be a trade-off to be made between caring and earning. This paper reports what is to our knowledge the first ever investigation of this issue from the male perspective.

In previous work (Carmichael and Charles, 1998, 1999) using the 1985 General Household Survey and its follow-up, the 1990 GHS we investigated, the impact of informal care responsibilities on the labour market behaviour of women-the traditional and still the numerically more important source of informal care. We found that working aged female informal carers were earning less per hour than would have been expected given their human capital. In addition, more committed female carers were less likely to participate in the formal labour market than otherwise similar non-carers. In this paper, we turn our attention to men, comparing and contrasting the labour market experience of male carers with that of their female counterparts.

\footnotetext{
${ }^{2}$ This stance towards community care is longstanding. See, for example, Department of Health (1989), para 1.9 and earlier reports dating back to 1957 (see Rowlands and Parker, 1998, v).

3 Department of Health (1998), paras 2.7 and 2.10.

4 Department of Health (1998), para 2.11.

5 The national strategy for carers (Department of Health, 1999) acknowledges that a majority of working-age carers are in paid employment and therefore flexibility needs to be a key theme in any package of support.

6 The 1985 General Household survey was the first ever large scale official survey of informal care activity in the UK and included a series of question designed to identify carers and provide information about them. A similar set of questions was included in the 1990 and 1995 surveys and more recently a new question on informal care responsibilities were included in the 2001 census. The data set used in this paper is extracted from the 1990 GHS, the 1995 data was not available when the study was initiated, however, Rowlands and Parker (1998) report some findings from a mainly bivariate analysis of the 1995 data and also provide a useful comparison with findings from the 1985 and 1990 data sets.
} 
The plan of the paper is as follows. In Section 2, we describe our dataset and discuss some summary statistics relating to the prevalence of male and female carers. Section 3 outlines the empirical model and in Section 4 we summarise and interpret the results of the empirical estimation. Section 5 concludes with some policy implications.

\section{The prevalence and labour force characteristics of male and female carers}

The data used for this study is the 1990 GHS. We analyse a sub-sample of female respondents between the ages of 18 and 59 years and a sub-sample of male respondents between the ages of 18 and 64 years. We exclude those still in full time education, those permanently unable to work due to ill health, those on government training and employment programmes and those in self-employment. ${ }^{7}$ This gives a total of 5463 female sample members and 4635 males.

Any impact on the labour supply and earnings of carers is likely to depend on the extent of the caring commitment involved. The GHS data allows three approximations to the degree of commitment: (i) self-reported weekly care hours, (ii) degree of responsibility for any dependent in terms of whether the respondent is the sole main, joint main or subsidiary carer of a dependent living at the same address or living at a different address ${ }^{8}$ and (iii) whether the dependent is incapacitated enough to be claiming Attendance Allowance (ATTAL). The summary statistics reported in Tables 1-3 take a preliminary look at the relationship between each of these three proxies for caring commitment and labour supply and earnings.

Table 1 show that, $18.34 \%$ of women in our sub-sample but only $13.2 \%$ of men were engaged in informal care activity on a regular basis. ${ }^{9}$ These figures are consistent with the

\footnotetext{
${ }^{7}$ We exclude the self-employed because a significant number of self-employed respondents report incredibly long working weeks and/or incredibly small (including negative) earnings, the raw data from which the wage rate is calculated. Whilst these figures are difficult to credit, they are not impossibly so—-some forms of self-employment probably do involve highly variable work patterns, others may allow for the mixing of work and non-work activities at the same time. Whatever the explanation, the data is problematic to use and could give misleading results, and so the self-employed were excluded from the analysis. This is regrettable since, as pointed out by one of the referees, it is possible that certain types of self-employment (e.g. those which permit one to work from home) might be particularly attractive to carers. However, an examination of the original data set provides no evidence that a disproportionate number of working carers were self-employed. Within the male sample, $13.3 \%$ of the self-employed were carers compared to $13 \%$ of the employed. Amongst the female sample, the figures are 23.4 and $17.4 \%$. However, as our results suggest that caring commitments impact on ability to work only when they are substantial, the more relevant figures are $30.1 \%$ of self-employed carers compared with $34.2 \%$ of employed ones report that caring takes up at least $10 \mathrm{~h}$ of their time each week, and $32.5 \%$ of self-employed carers compared with $31.2 \%$ of employed ones regard their caring role as being subsidiary to another 'main' carer. These figures, added to the fact that self-employment is relatively uncommon (less than $10 \%$ of the original sample were self-employed) lead us to conclude that the exclusion of the self-employed from the subsequent analysis has not introduced serious distortions.

${ }^{8}$ The GHS classifies a respondent as a main sole carer if no one else spends more time looking after their dependent, for example, another member of the family, a relative or friend or some kind of paid helper. If some other helper spends the same amount of time looking after the dependent as the respondent then the latter is classified as a main joint carer. The respondent is classified as a subsidiary carer if someone else qualifies as the main sole carer.

9 These figures are only a little different than those for the whole GHS sample; 17 and $13 \%$, respectively. In the 1985 and 1995 GHS the corresponding figures were somewhat lower; 15 and $12 \%$ in 1985 and 14 and $11 \%$ in 1990, respectively, for women and men. Rowlands and Parker (1998) suggest that these differences are explained
} 
Table 1

Care hours, participation and earnings of female and male carers

\begin{tabular}{|c|c|c|c|}
\hline $\begin{array}{l}\text { Self-estimated care hours } \\
\text { per week }\end{array}$ & $\begin{array}{l}\text { Number of carers } \\
(\% \text { all carers })\end{array}$ & $\begin{array}{l}\text { Number working } \\
\text { (employment rate, \%) }\end{array}$ & $\begin{array}{l}\text { Average wage rate } \\
\text { per hour }(£)^{\mathrm{a}}\end{array}$ \\
\hline \multicolumn{4}{|l|}{ (a) Female carers } \\
\hline$<5$ & $318(31.74)$ & $230(72.33)$ & 5.23 \\
\hline $5-9$ & $270(26.95)$ & $190(70.37)$ & 4.73 \\
\hline $10-19$ & $213(21.26)$ & $137(64.32)$ & 4.73 \\
\hline $20-34$ & $69(6.89)$ & $38(55.07)$ & 4.82 \\
\hline $35-49$ & $39(3.89)$ & $21(53.85)$ & 4.11 \\
\hline$>50$ & $93(9.28)$ & $22(23.66)$ & 3.77 \\
\hline All carers & $1002(100)$ & $638(63.67)$ & 4.86 \\
\hline Non-carers (4461) & - & $3032(68)$ & 5.18 \\
\hline All sub-sample (5463) & - & $3670(67.18)$ & 5.12 \\
\hline \multicolumn{4}{|l|}{ (b) Male carers } \\
\hline$<5$ & 267 (43.6) & $231(86.52)$ & 13.72 \\
\hline $5-9$ & $168(27.5)$ & $146(86.9)$ & 10.37 \\
\hline $10-19$ & 85 (13.9) & $62(72.94)$ & 10.53 \\
\hline $20-34$ & $39(6.4)$ & $24(61.54)$ & 8.52 \\
\hline $35-49$ & $22(3.6)$ & $12(54.55)$ & 10.36 \\
\hline$>50$ & $31(5.1)$ & $22(70.97)$ & 7.45 \\
\hline All carers & $612(100)$ & $497(81)$ & 11.73 \\
\hline Non-carers (4023) & - & $3446(85.66)$ & 12.45 \\
\hline All sub-sample (4635) & - & $3943(85)$ & 12.36 \\
\hline
\end{tabular}

Source: GHS (1990).

a Averaged over those working.

traditionally held view that women are more likely to be involved in informal care than men, but show a surprising number of men caring even so. The first column of Table 1 summarises information on the self-estimated amount of time usually spent caring each week and reveals a highly skewed distribution for both male and female carers. However, the male distribution is more so, with over $70 \%$ of all male carers caring for less than $10 \mathrm{~h}$ a week. ${ }^{10}$ Basic information on the labour supply of carers is contained in column 2. For female carers, the employment rate steadily declines as hours of caring increase. Approximately, the same pattern can be observed for male carers but the decline is much less pronounced. For both men and women the employment rate is less for carers who care for 10 or more hours a week than

by people in the 1990 survey identifying themselves as carers at relatively low levels of caring activity for a variety of reasons including small differences in the wording of questions. This explanation is consistent with the finding that the differences are much less for those involved in heavier caring responsibilities. For example, the percentage of all respondents in the whole sample who were main carers or who were caring for at least $20 \mathrm{~h}$ a week was the same (8 and 4\%, respectively) in 1990 as in 1995 (Rowlands and Parker, 1998).

10 The skewness identified above appears to have be less pronounced in the 1995 GHS where only $51 \%$ of male carers in the whole sample reported less than $10 \mathrm{~h}$ of caring a week compared with 62 and $61 \%$ in the 1985 and 1990 surveys, respectively (the corresponding figures for women are 54, 55 and 46\% in 1985, 1990, and 1995, respectively). These figures are consistent with the explanation given in Rowlands and Parker (1998) as outlined in the previous footnote. 
Table 2

Caring responsibilities, participation, and earnings of female and male main carers ${ }^{\mathrm{a}}$

\begin{tabular}{|c|c|c|c|}
\hline Responsibility of carer & $\begin{array}{l}\text { Number of carers } \\
\text { (\% of all carers })\end{array}$ & $\begin{array}{l}\text { Number working } \\
\text { (employment rate) }\end{array}$ & $\begin{array}{l}\text { Average wage rate } \\
\text { per hour }(£)^{b}\end{array}$ \\
\hline \multicolumn{4}{|l|}{ (a) Female main carers } \\
\hline $\begin{array}{l}\text { Sole main carer for dependent in } \\
\text { household }\end{array}$ & $156(15.52)^{\mathrm{c}}$ & $68(43.59)$ & 4.55 \\
\hline $\begin{array}{l}\text { Sole main carer for dependent } \\
\text { outside household }\end{array}$ & $391(38.91)^{\mathrm{c}}$ & $257(65.73)$ & 5.06 \\
\hline $\begin{array}{l}\text { Joint main carer for dependent in } \\
\text { household }\end{array}$ & $17(1.69)^{\mathrm{d}}$ & $9(52.94)$ & 4.26 \\
\hline $\begin{array}{l}\text { Joint main carer for dependent } \\
\text { outside household }\end{array}$ & $127(12.64)^{\mathrm{d}}$ & $82(64.57)$ & 4.22 \\
\hline $\begin{array}{l}\text { Secondary carer for dependent in } \\
\text { household }\end{array}$ & $13(1.29)$ & $11(84.62)$ & 4.16 \\
\hline $\begin{array}{l}\text { Secondary carer for dependent } \\
\text { outside household }\end{array}$ & $301(29.95)$ & $215(71.43)$ & 5.28 \\
\hline \multicolumn{4}{|l|}{ (b) Male main carers } \\
\hline $\begin{array}{l}\text { Sole main carer for dependent in } \\
\text { household }\end{array}$ & $71(11.43)^{\mathrm{e}}$ & $42(59.16)$ & 6.84 \\
\hline $\begin{array}{l}\text { Sole main carer for dependent } \\
\text { outside household }\end{array}$ & $149(24.00)^{\mathrm{e}}$ & $117(78.52)$ & 10.26 \\
\hline $\begin{array}{l}\text { Joint main carer for dependent in } \\
\text { household }\end{array}$ & $17(2.74)$ & $13(76.47)$ & 9.99 \\
\hline $\begin{array}{l}\text { Joint main carer for dependent } \\
\text { outside household }\end{array}$ & $97(15.62)$ & $83(85.57)$ & 9.81 \\
\hline $\begin{array}{l}\text { Secondary carer for dependent in } \\
\text { household }\end{array}$ & $43(6.92)^{f}$ & $36(83.72)$ & 10.07 \\
\hline $\begin{array}{l}\text { Secondary carer for dependent } \\
\text { outside household }\end{array}$ & $244(39.29)^{\mathrm{f}}$ & $213(87.30)$ & 14.44 \\
\hline $\begin{array}{l}\text { Source: GHS (1990). } \\
\quad{ }^{\text {a }} \text { Totals are less than in Table } 1 \mathrm{~d} \\
{ }^{\mathrm{b}} \text { Averaged over those working. } \\
{ }^{\mathrm{c}} \text { Includes } 18 \text { sole main carers for } \\
{ }^{\mathrm{d}} \text { Includes } 3 \text { joint main carers for } \\
{ }^{\mathrm{e}} \text { Includes } 14 \text { sole main carers for } \\
{ }^{\mathrm{f}} \text { Includes } 2 \text { secondary carers for }\end{array}$ & $\begin{array}{l}\text { missing data. } \\
\text { endents in and outs } \\
\text { ndents in and outsi } \\
\text { endents in and outs } \\
\text { ndents in and outsi }\end{array}$ & $\begin{array}{l}\text { usehold. } \\
\text { isehold. } \\
\text { usehold. } \\
\text { isehold. }\end{array}$ & \\
\hline
\end{tabular}

it is for the average non-carer. Column 3 shows the hourly gross earnings of working male and female carers. The figures show that for both groups earnings decline as the commitment to caring increases and if anything the decline is sharper for male carers. For both sexes, workers who also care for at least $5 \mathrm{~h}$ a week earn less than the average working non-carer.

Table 2 summarises information on the responsibilities of carers according to whether they are classified as the main carer (with joint or sole responsibilities) for any dependent and whether they are caring for someone in or outside their own household. The first columns of Table 2 show that most carers are caring for someone outside their household and most are main carers. However, a greater proportion of female carers are main (sole or joint) carers and over half the female carers are sole main carers. Columns 3 and 4 of Table 2 show basic information on the labour supply and earnings of main and other carers. The data show that 
Table 3

Care hours, caring responsibilities and labour market behaviour of carers with dependents claiming Attendance Allowance

\begin{tabular}{|c|c|c|c|c|c|c|c|c|}
\hline & Number & $\begin{array}{l}\text { Number caring } \\
10 \text { or more } \\
\text { hours per week }\end{array}$ & $\begin{array}{l}\text { Number of } \\
\text { main carers }\end{array}$ & $\begin{array}{l}\text { Number working } \\
\text { (employment rate, \%) }\end{array}$ & $\begin{array}{l}\text { Number working } \\
\text { full time, }>35 \mathrm{~h} \text { a } \\
\text { week }\end{array}$ & $\begin{array}{l}\text { Number caring } 10 \text { or } \\
\text { more hours a week and } \\
\text { working (full time) }\end{array}$ & $\begin{array}{l}\text { Number of main } \\
\text { carers working } \\
\text { (full time) }\end{array}$ & $\begin{array}{l}\text { Average wage } \\
\text { rate }^{\mathrm{a}}(\mathfrak{f} / \mathrm{h}) \\
(\text { full time) }\end{array}$ \\
\hline Females & 44 & 40 & 42 & 8 (18.18) & 4 & $6(3)$ & $8(4)$ & $3.28(3.20)$ \\
\hline Males & 25 & 18 & 18 & $15(60)$ & 12 & $10(7)$ & $10(7)$ & $5.44(5.92)$ \\
\hline
\end{tabular}

Source: GHS (1990).

${ }^{\text {a }}$ Averaged over those working. 
participation and earnings are generally lower for main carers (especially sole main carers with dependents in their household). A correlation between heavier caring responsibilities and lower earnings appears to be particularly evident in the male sub-sample.

A small sub-sample of dependents is able to claim some state support in the form of Attendance Allowance. To qualify for support, the dependent needs to satisfy an independent medical practitioner that he or she requires either frequent attention 'in connection with their bodily functions' or constant supervision 'to avoid substantial danger to themselves or to others'. These dependency criteria suggest that the payment of ATTAL will be indicative of a higher degree of responsibility on the part of the carer. This claim is supported by the figures in columns 2 and 3 of Table 3 which show that the majority of carers with dependents claiming ATTAL ${ }^{11}$ are main carers caring for more than $10 \mathrm{~h}$ per week. This is particularly the case for female carers. Column 4 shows that the payment of ATTAL also appears to have a negative effect on participation. Columns 6 and 7 show that this effect is strengthened by caring for more than $10 \mathrm{~h}$ a week and, for men, being a main carer. However, the direct effect of ATTAL on employment participation appears to be much stronger for women, even though the earnings of male carers with dependents in receipt of ATTAL are very low relative to average male earnings (column 8 ).

The negative correlation between the payment of ATTAL and employment status can be interpreted as suggesting that the payment of the benefit does identify those caring for the more heavily dependent who, because of their commitment to caring, are less likely to work. However, the payment of ATTAL could also have a negative impact on employment participation through a financial disincentive effect. ATTAL is paid to infirm individuals to allow the purchase of help that will enable claimants to continue to live outside of an institution. The money could therefore be being passed on to claimants' carers although claimants do not have to use the allowance for this. How much is actually passed on to carers is therefore not known but, to the extent that it is, the payment of this benefit may be expected to reduce the carer's incentive (or need) to work. However, the evidence of column 5 suggests that such an effect if it exists at all is weak especially for men, in that a considerable proportion of those working are continuing to work full time. Fifty percent of working females and $80 \%$ of working males with dependents in receipt of the allowance are working full time. The comparable figures for the whole female sample and the whole male sample are 59.97 and $72.05 \%$, respectively, while for all female carers and all male carers the comparable figures are 55.64 and $71.77 \%$. Columns 6 and 7 show that women with main carer responsibilities and/or caring for more than $10 \mathrm{~h}$ a week are equally likely to work full time as those without these extra responsibilities but men in the same position are a little less likely to be working full time than either the whole sample or carers overall.

To summarise, the data in Tables 1-3 show that there are similarities as well as differences between male and female carers. Both male and female carers are less likely to be in paid employment than non-carers and, for men as well as women, both the likelihood of working and earnings in paid work decline as the caring commitment increases. However, female carers are more likely to be main carers and tend to report longer care hours than male

\footnotetext{
11 Not all carers with dependents claiming ATTAL are identified in our sample, only those with a dependent who lives in the same household as the carer or who are claiming Invalid Care Allowance (ICA; one of the qualifying criteria for payment of ICA is that the carer's dependent is in receipt of ATTAL).
} 
carers. ${ }^{12}$ Male carers also appear to have a stronger attachment to work (relative to the male sub-sample as a whole). This is also true of carers with dependents claiming Attendance Allowance although in this case small numbers make generalisation difficult. Lastly, the earnings of male carers are lower relative to the male average than the earnings of female carers relative to the female average. However, given that average female earnings are anyway lower than average male earnings, female carers still earn less on average than male carers. ${ }^{13}$

\section{The empirical model}

In order to provide the first ever econometric evidence on the effect of caring amongst males and to do so in a way which permits comparison with female carers we investigate the effect of informal care within the context of a two-equation recursive model commonly used to investigate the relationship between female labour supply and earnings. By doing so we are treating men as women for the purposes of estimating their labour supply since we implicitly assume that the decision to participate in the labour market is not an automatic one but one based on a trade-off between the need to earn and the need to supply unpaid labour within the home. However, the model is estimated separately for each gender, thereby allowing the coefficients to differ in the standard way.

The model consists of a wage equation and a participation/labour supply equation derived from a neoclassical income-leisure choice model. The wage rate predicted from the wage equation (WAGEFIT) is used as an instrumental variable in the labour supply equation in place of the unknown rate the non-working members of the sample could have earned and, to avoid the possibility of introducing a systematic measurement bias, the known rate those in work were earning. The potential sample selection bias problem in estimating the wage and hours equations from the observations of the non-random, self-selected sample of workers is treated by the well established method of including the Heckman correction term as an additional regressor (Heckman, 1976). Further details of the model are in Appendix A; Appendix B contains definitions of the variables used in the analysis.

The impact of informal care responsibilities on employment (and earnings) is investigated by including independent variables indicating caring commitment in the estimated labour supply equations. Informal care responsibilities may influence labour supply decisions in three ways. Because of constraints on time, caring commitments may lead the individual to substitute unpaid for paid work-the substitution effect. However, the extra financial expenditure typically associated with informal care may give the individual an added motive to undertake unpaid work - the income effect. ${ }^{14}$ Similarly, the desire for a break from the emotional demands associated particularly with the care of the more highly dependent may give a motive to take on at least some hours of paid work away from the dependent— the

\footnotetext{
12 If, as discussed in Section 3, men are more likely than women to overstate reported care hours then the difference would be more dramatic than it appears in the statistics.

13 In Table 1, the female-male wage ratio is $41.4 \%$ which at first glance seems low in comparison with other data sets where a comparable rate of around $70 \%$ is more usual. However, comparing the wage rates of only the full time male and female workers in the sample gives a female-male wage ratio of $64.4 \%$ which is closer to the figures observed elsewhere, the difference reflecting differences in part time and full time hourly rates.

14 See Twigg and Atkin (1994), p. 42.
} 
respite effect. ${ }^{15}$ Given women's traditionally weaker attachment to the labour force and men's traditional role as the breadwinner we expect the substitution effect to be stronger, and the income and respite effects weaker for women.

The informal care variables included in the estimated equations are derived from the GHS data on caring commitment. Hours spent caring is the most obvious indicator of caring commitment. In the GHS data, care hours are not reported in continuous form but are instead grouped, with the classes as shown in Table 1 . The data therefore permits us to use either a complete set of dummy variables or to construct pairs of dichotomous variables defined on whether the sample member is an informal carer caring for less than or at least a threshold number of hours a week. On the basis of the results from our earlier work on female carers in the 1990 GHS (Carmichael and Charles, 1999) and preliminary work on male carers not reported here, we opt for the latter and adopt a $10 \mathrm{~h}$ threshold. Thus, we use two dichotomous variables indicating whether a carer is caring for less than or at least $10 \mathrm{~h}$ a week (CARE $<10 \mathrm{HRS}$ and $\mathrm{CARE} \geq 10 \mathrm{HRS})$. Our rationale is that the degree of responsibility involved in caring for less than $10 \mathrm{~h}$ week is likely to be relatively minor one associated with supporting someone who needs no more than a regular but relatively undemanding, 'bit of help'. On the other hand, care hours of 10 or more a week imply more than this and may involve caring for someone who needs considerable care and/or supervision.

In our earlier work on female carers, we found that women spending more than $10 \mathrm{~h}$ a week on caring activities and/or with dependents in receipt of ATTAL were less likely to work than otherwise similar non-carers. These results are consistent with the hypothesis that for more committed carers the substitution effect dominates. However, the self-reported nature of the care hours data presents some problems in that the measure is likely to be inaccurate not least because, as pointed out by an anonymous referee, men and women might employ different implicit definitions of care inputs and hours because of their traditionally different expectations about carrying out household tasks. If this is so, the estimations will tend to exaggerate the caring demands faced by men, compared to women. Because of these concerns we constructed additional indicators of informal care commitments from the GHS data recording different categories of responsibility for caring. The alternative variables indicate whether or not the carer is a main carer (sole or joint) caring for a dependent in or outside the carer's own household (MAIN CARER IN, MAIN CARER OUT, NMAIN CARER IN and NMAIN CARER OUT). The distinction between caring in or outside the household is made because it seems likely to affect the demands faced by carers. Caring for someone who lives with the carer is likely to involve more round-the-clock activity than otherwise. On the other hand, there may be more room for flexibility in the provision of care for someone in the same household. In other words, caring for someone in or outside the household may constrain the carer in different ways. ${ }^{16}$ In the employment participation

\footnotetext{
15 See Parker (1993) and Twigg and Atkin (1994).

16 As pointed out by one of the referees there is a further distinction between co-resident and non-co-resident carers in that co-resident carers might do more caring but would also have greater difficulty deciding what is and what is not 'informal care'. The latter may therefore under-report their hours of caring. This possibility gives further justification for the use of this alternative set of informal care indicators. However, as pointed out by the same referee there may be a gender difference in the categorisation given the traditional caring/home-making role traditionally associated with women.
} 
equation, we also include a dichotomous independent variable indicating the payment of Attendance Allowance to a carer's dependent, DEPATTAL.

To summarise, our main hypotheses are as follows: first that the impact of informal care on labour supply will depend on the nature and sizes of the income, respite and substitution effects. Given the traditionally stronger attachment of males to the labour force we expect the substitution effect of informal care to be weaker for male carers and therefore expect caring responsibilities to have a stronger negative effect on female labour supply. Second, we expect the impact of informal care on labour supply to depend on the degree of caring commitment as indicated by longer care hours, a main carer role or the payment of ATTAL.

\section{Results}

Tables 4-6 show the results of our estimation procedure. The first set of results, reported in Table 4, show the direct impact of informal care commitments on labour supply. The results in Tables 5 and 6 additionally allow for effects of caring on the wage rate.

\subsection{The effects of caring on labour supply}

The basic econometric evidence on the labour supply effects of informal care is reported in Table 4. This contains the two specifications for informal care responsibilities discussed in Section 3: CARE $<10$ HRS and CARE $\geq 10$ HRS and MAIN CARER IN, MAIN CARER OUT, NMAIN CARER IN, NMAIN CARER OUT. Our primary interest is in the performance of these informal care variables and as most of the control variables behave as expected ${ }^{17}$ we turn directly to them.

A comparison of equation 4(i) with 4(iii) and 4(ii) with 4(iv) suggests that the impact of informal care on the labour supply of men and women is remarkably similar. In equations 4(i) and 4(iii), the indicators of caring commitment are CARE $<10$ HRS and CARE $\geq 10$ HRS. The influence of the former is not significant in either estimation indicating that the labour supply of both male and female carers caring for less than $10 \mathrm{~h}$ a week is not significantly different from that of non-carers. In contrast, the influence of CARE $\geq 10 H R S$ is negative and highly significant in equations 4(i) and 4(iii) indicating that both men and women caring for more than $10 \mathrm{~h}$ a week are significantly less likely to be working than similarly qualified non-carers. However, the payment of ATTAL only exerts a significant negative influence on female participation. These results suggest that for all carers committed to helping their dependents for 10 or more hours a week and for female carers with a dependent in receipt of ATTAL, the substitution effect of informal care on participation outweighs the respite and income effects.

In equations 4(ii) and 4(iv), indicators of caring responsibility are employed as an alternative surrogate for the extent of caring commitment. Again, we find that there are similarities

\footnotetext{
17 The signs on all the control variables are as predicted by standard neo classical theory of labour supply with the exception of the positive sign on OTHINH in the male participation equations. One interpretation of this result is simply that men with working wives are more likely to be working themselves and this over-rides the negative effect which is evident in the female sample.
} 
Table 4

Hours of caring, caring responsibilities and employment participation with WORK as the dependent variable

\begin{tabular}{|c|c|c|c|c|}
\hline \multirow[t]{2}{*}{ Independent variables } & \multicolumn{2}{|l|}{ Female sample } & \multicolumn{2}{|l|}{ Male sample } \\
\hline & Equation 4(i) & Equation 4(ii) & Equation 4(iii) & Equation 4(iv) \\
\hline CARE $<10$ HRS & $0.06628(1.033)$ & & $0.0185(0.189)$ & \\
\hline MAIN CARER IN & & $-0.3555\left(-2.996^{* * *}\right)$ & & $-0.4087\left(-2.311^{* *}\right)$ \\
\hline MAIN CARER OUT & & $-0.122\left(-1.87^{*}\right)$ & & $-0.2393\left(-2.033^{* *}\right)$ \\
\hline NMAIN CARER IN & & $0.1094(0.243)$ & & $-0.0095(-0.032)$ \\
\hline NMAIN CARER OUT & & $0.0858(0.983)$ & & $0.0899(0.699)$ \\
\hline DEPATTAL & $-1.023\left(-4.24^{* * *}\right)$ & $-0.9469\left(-3.773^{* * *}\right)$ & $-0.2061(-0.657)$ & $-0.2251(-0.669)$ \\
\hline WAGEFIT $^{\mathrm{a}}$ & $1.488\left(20.167^{* * *}\right)$ & $1.3555\left(18.715^{* * *}\right)$ & $2.336\left(24.005^{* * *}\right)$ & $2.3147\left(23.899^{* * *}\right)$ \\
\hline OTHINCO & $-0.000056\left(-11.467^{* * *}\right)$ & $-0.000055\left(-11.367^{* * *}\right)$ & $-0.000034\left(-13.892^{* * *}\right)$ & $-0.000034\left(-13.886^{* * *}\right)$ \\
\hline OTHINCH & $-0.000003\left(-2.513^{* * *}\right)$ & $-0.000002\left(-2.377^{* * *}\right)$ & $0.000012\left(5.789^{* * *}\right)$ & $0.000012\left(5.863^{* * *}\right)$ \\
\hline AGE & $-0.0136\left(-6.609^{* * *}\right)$ & $-0.014\left(-6.791^{* * *}\right)$ & $-0.0246\left(-11.557^{* * *}\right)$ & $-0.0243\left(-11.404^{* * *}\right)$ \\
\hline CHILD $<2$ & $-1.459\left(-20.896^{* * *}\right)$ & $-1.4076\left(-22.53^{* * *}\right)$ & $-0.0094(-0.095)$ & $-0.016(-0.163)$ \\
\hline CHILD2-4 & $-1.034\left(-15.056^{* * *}\right)$ & $-0.8555\left(-10.262^{* * *}\right)$ & $-0.2022(-1.134)$ & $-0.2028(-1.347)$ \\
\hline CHILD5-10 & $-0.3554\left(-6.035^{* * *}\right)$ & $-0.3563\left(-6.065^{* * *}\right)$ & $-0.0396(-0.376)$ & $-0.0 .437(-0.416)$ \\
\hline CONSTANT & $-7.284\left(-14.419^{* * *}\right)$ & $-6.5192\left(-13.07^{* * *}\right)$ & $-12.134\left(-17.174^{* * *}\right)$ & $-12.006\left(-17.07^{* * *}\right)$ \\
\hline REGIONAL DUMMIES & Yes & Yes & Yes & Yes \\
\hline log likelihood & -2710.201 & -2736.09 & -1323.705 & -1328.136 \\
\hline$\chi^{2}$ & $1468.747^{* * *}$ & $1393.412^{* * *}$ & $1229.918^{* * *}$ & $1215.311^{* * *}$ \\
\hline Likelihood ratio index & 0.213197 & 0.20296 & 0.317208 & 0.313906 \\
\hline$\%$ Correct & 76 & 77 & 90 & 84 \\
\hline No. of observations ${ }^{b}$ & 5443 & 5426 & 4618 & 4611 \\
\hline
\end{tabular}

The $t$ statistics are in parenthesis.

${ }^{a}$ The earnings Eq. (1) estimated to obtain WAGEFIT do not include any indicators of informal care. Otherwise they are identical to the formulations in Tables 5 and 6.

b Number is less than full sample because of missing data for YRSOUT and main carer responsibilities.

* Indicates significance at the $10 \%$ level.

** Indicates significance at the 5\% level.

*** Indicates significance at the $1 \%$ level. 
Table 5

Hours of caring, earnings and employment

\begin{tabular}{|c|c|c|c|c|}
\hline \multirow[t]{3}{*}{ Independent variables } & \multicolumn{2}{|l|}{ Female sample } & \multicolumn{2}{|l|}{ Male sample } \\
\hline & $\ln \mathrm{WAGEa}^{\mathrm{a}}$ & WORK $^{\mathrm{a}}$ & $\ln$ WAGE & WORK \\
\hline & Equation 5(i) & Equation 5(ii) & Equation 5(iii) & Equation 5(iv) \\
\hline CARE $<10$ HRS & $-0.0531\left(-1.7^{*}\right)$ & $0.1528\left(2.358^{* *}\right)$ & $-0.0293(-0.798)$ & $0.0804(0.789)$ \\
\hline $\mathrm{CARE} \geq 10 \mathrm{HRS}$ & $-0.0873\left(-2.057^{* *}\right)$ & $-0.1802\left(-2.382^{* *}\right)$ & $-0.1838\left(-2.891^{* * *}\right)$ & $-0.0395(-0.294)$ \\
\hline DEPATTAL & & $-1.0295\left(-4.23^{* * *}\right)$ & & $-0.2131(-0.656)$ \\
\hline WAGEFIT & & $1.6644\left(22.057^{* * *}\right)$ & & $2.7239\left(26.039^{* * *}\right)$ \\
\hline OTHINCO & & $-0.00006\left(-11.785^{* * *}\right)$ & & $-0.000037\left(-14.993^{* * *}\right)$ \\
\hline OTHINCOH & & $-0.000003\left(-2.778^{* * *}\right)$ & & $0.000013\left(5.962^{* * *}\right)$ \\
\hline AGE & & $-0.0133\left(-6.402^{* * *}\right)$ & & $-0.0278\left(-12.57^{* * *}\right)$ \\
\hline YRSOUT & $0.0338\left(9.037^{* * *}\right)$ & & $0.079\left(22.061^{* * *}\right)$ & \\
\hline YRSOUTSQ & $-0.0007\left(-8.356^{* * *}\right)$ & & $-0.0014\left(-18.442^{* * *}\right)$ & \\
\hline EDLEVA & $0.9838\left(8.329^{* * *}\right)$ & & $0.8853\left(10.908^{* * *}\right)$ & \\
\hline EDLEVB & $0.9516\left(20.961^{* * *}\right)$ & & $0.8907\left(20.39^{* * *}\right)$ & \\
\hline EDLEVC & $0.7646\left(20.128^{* * *}\right)$ & & $0.5443\left(13.67^{* * *}\right)$ & \\
\hline EDLEVD & $0.3045\left(11.792^{* * *}\right)$ & & $0.3002\left(10.033^{* * *}\right)$ & \\
\hline EDLEVF & $0.5098\left(5.157^{* * *}\right)$ & & $0.379\left(3.368^{* *}\right)$ & \\
\hline CHILD $<2$ & & $-1.46\left(-20.708^{* * *}\right)$ & & $-0.0553(-0.537)$ \\
\hline CHILD2-4 & & $-1.03\left(-14.862^{* * *}\right)$ & & $-0.2991\left(-1.898^{*}\right)$ \\
\hline CHILD5-10 & & $-0.3507\left(-5.904^{* * *}\right)$ & & $-0.1201(-1.09)$ \\
\hline CHILD11-16 & & $0.0716(1.083)$ & & $-0.1558(-1.255)$ \\
\hline$\lambda(\mathrm{LAMBDA})$ & $0.0427(0.94)$ & & $0.1131\left(1.69^{*}\right)$ & \\
\hline CONSTANT & $5.2591\left(34.213^{* * *}\right)$ & $-8.2792\left(-16.152^{* * *}\right)$ & $5.2589\left(33.452^{* * *}\right)$ & $-14.292\left(-19.139^{* * *}\right)$ \\
\hline CHILD BORN DUMMIES & Yes & No & No & No \\
\hline REGIONAL DUMMIES & Yes & Yes & Yes & Yes \\
\hline Adj. $R^{2}$ & 0.239 & & 0.227 & \\
\hline$F$ & $32.91^{* * *}$ & & $38.1^{* * *}$ & \\
\hline log likelihood & & -2657.489 & & -1215.577 \\
\hline$\chi^{2}$ & & $1574.172^{* * *}$ & & $1446.173^{* *}$ \\
\hline Likelihood ratio index & & 0.2285 & & 0.372982 \\
\hline$\%$ Correct & & 76.34 & & 94.45 \\
\hline No. of observations & 3653 & 5443 & 3943 & 4618 \\
\hline
\end{tabular}

The $t$ statistics are in parenthesis

${ }^{a}$ Dependent variables.

* Indicates significance at the $10 \%$ level.

** Indicates significance at the 5\% level.

*** Indicates significance at the $1 \%$ level. 
Table 6

Caring responsibilities, earnings and employment

\begin{tabular}{|c|c|c|c|c|}
\hline \multirow[t]{2}{*}{ Independent variables } & \multicolumn{2}{|l|}{ Female sample } & \multicolumn{2}{|l|}{ Male sample } \\
\hline & $\begin{array}{l}\text { ln WAGEa }{ }^{a} \\
\text { Equation } 6(\mathrm{i})\end{array}$ & $\begin{array}{l}\text { WORK }^{\mathrm{a}} \\
\text { Equation 6(ii) }\end{array}$ & $\begin{array}{l}\text { ln WAGE } \\
\text { Equation 6(iii) }\end{array}$ & $\begin{array}{l}\text { WORK } \\
\text { Equation 6(iv) }\end{array}$ \\
\hline MAIN CARER IN & $-0.1718\left(-2.471^{* *}\right)$ & $-0.0675(-0.556)$ & $-0.2299\left(-2.467^{* *}\right)$ & $0.2083(1.121)$ \\
\hline MAIN CARER OUT & $-0.073\left(-2.119^{* *}\right)$ & $-0.0079(-0.119)$ & $-0.1156\left(-2.335^{* *}\right)$ & $0.0357(0.29)$ \\
\hline NMAIN CARER IN & $-0.0209(-0.118)$ & $0.1414(0.31)$ & $-0.1439(-1.282)$ & $0.3857(1.227)$ \\
\hline NMAIN CARER OUT & $-0.0207(-0.493)$ & $0.1225(1.377)$ & $0.0424(0.893)$ & $-0.0417(-0.31)$ \\
\hline DEPATTAL & & $-0.9581\left(-3.759^{* * *}\right)$ & & $-0.2616(-0.749)$ \\
\hline WAGEFIT & & $1.6875\left(22.322^{* * *}\right)$ & & $2.7254\left(26.024^{* * *}\right)$ \\
\hline OTHINCO & & $-0.00006\left(-11.966^{* * *}\right)$ & & $-0.00004\left(-15.011^{* * *}\right)$ \\
\hline OTHINCH & & $-0.000003\left(-2.874^{* * *}\right)$ & & $0.00001\left(6.043^{* * *}\right)$ \\
\hline AGE & & $-0.0129\left(-6.201^{* * *}\right)$ & & $-0.0279\left(-12.581^{* * *}\right)$ \\
\hline YRSOUT & $0.0337\left(9.04^{* * *}\right)$ & & $0.0791\left(22.056^{* * *}\right)$ & \\
\hline YRSOUTSQ & $-0.0007\left(-8.313^{* * *}\right)$ & & $-0.0014\left(-18.422^{* * *}\right)$ & \\
\hline EDLEVA & $0.9838\left(8.319^{* * *}\right)$ & & $0.881\left(10.862^{* * *}\right)$ & \\
\hline EDLEVB & $0.9549\left(20.979^{* * *}\right)$ & & $0.8619\left(20.401^{* * *}\right)$ & \\
\hline EDLEVC & $0.7683\left(20.168^{* * *}\right)$ & & $0.5416\left(13.618^{* * *}\right)$ & \\
\hline EDLEVD & $0.3065\left(11.832^{* * *}\right)$ & & $0.2993\left(10.006^{* * *}\right)$ & \\
\hline EDLEVF & $0.512\left(5.176^{* * *}\right)$ & & $0.3749\left(3.334^{* * *}\right)$ & \\
\hline CHILD $<2$ & & $-1.4047\left(-22.115^{* * *}\right)$ & & $-0.0642(-0.623)$ \\
\hline CHILD2-4 & & $-0.8422\left(-9.931^{* * *}\right)$ & & $-0.3046\left(-1.933^{*}\right)$ \\
\hline CHILD5-10 & & $-0.3457\left(-5.794^{* * *}\right)$ & & $-0.129(-1.172)$ \\
\hline CHILD11-16 & & $0.0735(1.11)$ & & $-0.1602(-1.29)$ \\
\hline$\lambda(\mathrm{LAMBDA})$ & $0.0447(0.983)$ & & $0.1129\left(1.688^{*}\right)$ & \\
\hline CONSTANT & $5.2524\left(34.114^{* * *}\right)$ & $-8.3985\left(-16.375^{* * *}\right)$ & $5.267\left(33.546^{* * *}\right)$ & $-14.311\left(-19.161^{* * *}\right)$ \\
\hline CHILD BORN DUMMIES & Yes & No & No & No \\
\hline REGIONAL DUMMIES & Yes & Yes & Yes & Yes \\
\hline Adj. $R^{2}$ & 0.24 & & 0.227 & \\
\hline$F$ & $31.23^{* * *}$ & & $36.03^{* * *}$ & \\
\hline log likelihood & & -5639.591 & & -1216.365 \\
\hline$\chi^{2}$ & & $1586.41^{* * *}$ & & $1438.853^{* * *}$ \\
\hline Likelihood ratio index & & 0.231067 & & 0.37145 \\
\hline$\%$ Correct & & 76.37 & & 89.03 \\
\hline No. of observations & 3604 & 5426 & 3924 & 4611 \\
\hline
\end{tabular}

The $t$ statistics are in parenthesis

${ }^{\text {a }}$ Dependent variables.

* Indicates significance at the $10 \%$ level.

** Indicates significance at the 5\% level.

*** Indicates significance at the $1 \%$ level. 
in the impact of informal care on the labour supply of men and women. In neither equation is the influence of either indicator of secondary responsibility (NMAIN CARER IN, NMAIN CARER OUT) significant implying that the labour supply of both male and female secondary carers is not significantly different from that of non-carers. However, the influence of MAIN CARER IN is negative and highly significant in both equations 4(ii) and 4(iv) while the influence of MAIN CARER OUT is negative but much smaller in absolute terms and somewhat less significant (especially in the female participation equation). These results indicate that main carers (especially those caring for a dependent inside their own household) are significantly less likely to be working than comparable non-carers. For male main carers caring for a dependent outside the household the negative effect on the probability of working is stronger than it is for women but the payment of ATTAL is only significant in the female employment equation. These results suggest that for main carers, as for carers committed for longer hours, the substitution effect of informal care on participation outweighs the respite and income effects and this is true for men as well as women.

On the basis of the results in Table 4, it is possible to calculate the opportunity costs of caring by calculating predicted probabilities at the mean (see Greene, 1993, p. 637-643). Using this approach, the opportunity costs of caring in terms of expected foregone earnings are $\bar{w}_{\mathrm{o}}\left(p_{\mathrm{nc}}-p_{\mathrm{c}}\right)$, where $\bar{w}_{\mathrm{o}}$ is the predicted offered wage ( $\left.e^{\mathrm{WAGEFIT}}\right)$ for the mean sample member ( $£ 7.49$ for men and $£ 3.11$ for women) and $p_{\text {nc }}$ and $p_{\mathrm{c}}$ are the probabilities that the mean sample member is working for a non-carer and a carer, respectively. ${ }^{18}$ If we consider carers committed to 10 or more hours of informal care per week with dependents not in receipt of ATTAL then for the mean female sample member $p_{\mathrm{nc}}-p_{\mathrm{c}}=0.123$ and annual foregone earnings amount to $£ 614.53$ (on the basis of average weekly hours of 30.82 ). For an equivalent male carer $p_{\mathrm{nc}}-p_{\mathrm{c}}=0.1165$ and annual foregone earning amount to $£ 1550.59$ (although the reduction in the probability of working is less for men the earnings loss is greater because male average earnings and hours of work are higher). The opportunity costs are higher still for female carers with dependents in receipt of ATTAL and amount to annual foregone earnings of $£ 1891.01$. Equivalent calculations can be performed to show similar foregone earnings losses for male and female main carers. ${ }^{19}$ These results imply that significant negative effects of informal care on the probability of employment for men as well as women involve non-trivial earnings losses for more committed carers.

\subsection{The effects of caring on the wage rate and the indirect effect of ability to earn on willingness to work}

Next we consider the possibility of a causal relationship from informal care to earnings by including indicators of caring commitment in the earnings equations and subsequently including the resulting fitted wage variable in the participation equations. The demands of informal care can be hypothesised to limit the job opportunities available to the individual

\footnotetext{
${ }^{18} p_{\mathrm{nc}}=\Phi\left(\sum \beta_{i} \bar{x}_{i}\right)$ and $p_{\mathrm{c}}=\Phi\left(\sum \beta_{i} \bar{x}_{i}+\alpha_{j}\right)$ where $\Phi$ is the cumulative density function, $\beta_{i}$ the estimated coefficient on the $i$ th non-caring variable and $\alpha_{j}$ the coefficient on the $j$ th caring variable ( $\alpha_{j}=0$ for non-carers); and $\bar{x}_{i}$ the mean value of the $i$ th independent variable.

19 For example, expected foregone earnings for female main carers with dependents in the same household who are not in receipt of ATTAL are $£ 693.91$ and for an equivalent male carer they are $£ 1248.49$.
} 
such that their earning power is depressed below that indicated by their human capital. In addition, informal care, like childcare responsibilities will have a direct effect on labour market experience and therefore wages if labour supply is reduced or withdrawn.

The results of these estimations are included in Tables 5 and 6 and show that when we allow for the possibility that informal care has a direct effect on earnings, some interesting differences emerge in the observed labour market behaviour of male and female carers. These results can be contrasted with those in Table 4 which were based on the assumption of no independent impact of informal care on the wage rate. Consequently, no informal care variables were included in the wage equations used to predict the fitted wage, WAGEFIT which constrained the wage of carers to be the same as that of otherwise similar non-carers. In Tables 5 and 6, the earnings of carers and non-carers are not constrained in this way.

Equation 5(i) shows that for women even low levels of caring commitment are consistent with lower earnings. However, the negative influence on the offered wage rate of women caring for more than $10 \mathrm{~h}$ a week is larger and more significant. In the male wage equation, CARE $\geq 10 \mathrm{HRS}$ is negative and significant at the $1 \%$ level but men caring for less than $10 \mathrm{~h}$ a week do not earn significantly less than comparable non-carers. Furthermore, the coefficients on CARE $\geq 10$ HRS are larger in the male wage equation and imply a wage reduction of around $18 \%$ for males caring for 10 or more hours a week while the wage reduction for a comparable female carer is just under $9 \%$. These results suggest that the negative influence of informal care on the offered wage rate is considerably more costly for male carers.

As a consequence of allowing for indirect wage effects the participation equations 5(ii) and 5(iv) are very different from equations 4(i) and 4(iii). In equation 5(ii), the highly significant positive coefficient on $\mathrm{CARE}<10 \mathrm{HRS}$ in the female labour market participation equation suggests that women who spend less than $10 \mathrm{~h}$ a week on caring activities are more likely to work than otherwise similar and equally low paid non-carers. This result is consistent with the hypothesis that, for this sub-group of female carers, it is the income and/or respite effects of caring which dominate. In contrast, the coefficient on CARE $\geq 10 \mathrm{HRS}$, although much less significant than in equation 4(i) is still negative and suggests that for this subgroup of more committed female carers the substitution effect is dominant. In addition, the negative and significant influence of DEPATTAL remains so and is consistent with the hypothesis that the group of carers identified by the payment of this benefit face heavier demands.

In the male participation equation, the pattern is very different. None of the caring variables are significant indicating that the negative significance of CARE $\geq 10 \mathrm{HRS}$ in equation 4(iii) is entirely due to the indirect wage effect and that male carers are no more or less likely to work than otherwise similar and equally low paid non-carers. This result is consistent with the hypothesis that for men the substitution effect and the income and respite effects are equally important. The lack of significance of DEPATTAL suggests that for men the income and respite effects are strong enough to counter any negative employment incentive effects associated with the payment of ATTAL.

The results in Table 6 are, as expected, similar to those in Table 5 but very much in contrast to those in Table 4. First of all the negative influence on earnings is only significant for main carers and the percentage reduction is again greater for men. Secondly, in the participation equations only the negative influence of DEPATTAL in the female participation equation is significant. These results suggest that the negative coefficients on MAIN CARER IN/OUT 
in equations 4(ii) and 4(iv) are entirely due to indirect wage effects. ${ }^{20}$ The insignificant effects of MAIN CARER IN/OUT in the male and female participation equations imply that for main carers the substitution and income/respite effect balance out. This result is in contrast to the negative significance of DEPATTAL and CARE $\geq 10 \mathrm{HRS}$ (in equation 5(ii)). One possible interpretation is that, for women at least, it is actual time spent caring rather than responsibility (or time spent caring relative to that of any other helper) that is the crucial determinate of whether an individual can simultaneously maintain a paid job and be committed to informal care. ${ }^{21}$

\subsection{Interpretation of results}

The relationship between the informal care indicators and participation in Tables 4-6 suggests that more committed male and female carers are less likely to work than otherwise similar non-carers but for different reasons. For females committed to at least $10 \mathrm{~h}$ of informal care a week the negative effect on employment is due to the combined impact of a lower ability to earn and a direct substitution effect. For males the lower probability of employment is due entirely to the indirect effect of lower ability to earn. So while at first sight the informal care effect on male and female participation appears very similar, this appearance is deceptive. Once the indirect earnings effect on participation is taken into account, a direct negative relationship between caring commitment and participation can only be identified for female carers. Our interpretation is that for some more committed female carers the negative substitution effect is dominant while for male carers the income (and possibly respite) effects are more compelling. This would not be altogether surprising and is consistent with the traditional bread winning role and stronger labour market attachment of males.

This interpretation relies on the assumption that informal care is exogenously determined, i.e. that the decision to supply care is made independently of the opportunity cost in terms of the rate of earnings foregone. Thus, the direction of causality is assumed to run unambiguously from informal care responsibilities to consequential effects on the wage rate which can be earned. However, causality could also run the other way: potential carers could be more likely to become carers, and to supply more care hours when they do so, the lower is the opportunity cost in terms of the wage rate they could earn. ${ }^{22}$ This

\footnotetext{
20 The greater earnings reduction for main carers when the dependent lives with the carer suggests that this group face the most demands-on their time and their physical, emotional and financial resources.

21 As noted the payment of ATTAL is likely to indicate a greater degree of dependency on the part of the dependent and there is therefore a degree of co-determination between the payment of ATTAL and both MAIN CARER IN/OUT and CARE $\geq 10$ HRS. The exclusion of DEPATTAL in the participation equations has no effect on the results for men but in equation 5(ii) the negative impact of CARE $\geq 10 \mathrm{HRS}$ is much more substantial and significant at the $1 \%$ level with very little effect on the significance of CARE $<10$ HRS. A similar effect on MAIN CARER IN is noted with the exclusion of DEPATTAL from equation 6(ii) - the former becomes significant at the $10 \%$ level and takes a negative sign.

22 For example, informal carers may have invested in less human capital and therefore earn systematically less than non-carers for reasons unrelated to their informal care responsibilities. However, we allow for human capital, albeit imperfectly and we have also investigated the possibility that carers as a group are characterised by lower human capital investment (in terms of educational attainment) but we found no compelling evidence that this was the case.
} 
argument rests on the assumption that caring is to at least some extent a matter of rational choice; i.e. that a potential carer, faced with a situation in which a person for whom she feels some degree of emotional commitment becomes infirm or chronic sick and in need of care, decides whether and how much of that care to supply on the basis of a rational (but not necessarily selfish) assessment of the costs and benefits. The major determinants of the caring decision are likely to be 'non-economic' factors such as the closeness of the kinship bond between the potential carer and dependent; the nature and strength of social mores operating on the potential carer; his or her ability to cope with the psychological and emotional demands of caring; and the geographical distance between their homes. But other more 'economic' factors might also play their part: the availability and cost of alternative sources of care; the financial means of the dependent and/or wider family; and the opportunity cost (in terms of both ability to earn and time) to the potential carer.

Such considerations suggest that it would be useful to estimate a more general allocationof-time model in which the caring and working decisions are made simultaneously. This would make caring endogenous and allow, in particular, the wage rate to influence the caring decision. Unfortunately, some important data limitations prevent us from estimating this more general model. First of all there is very little data on the non-economic determining factors - in particular, the degree of dependency of the potential dependent, something likely to be a major determinant on the caring side. Secondly the sample of non-carers will contain many respondents for whom the question of whether or not to take on informal care responsibilities has never arisen. We therefore cannot distinguish between sample members who are not carers because (a) there is no one amongst their family, etc. who needs care; or (b) there is someone for whom they could care, but they choose not. As the data do not allow us to distinguish the members of the (b) group from the great mass of (a) types the model we can estimate would be biased if caring is strongly endogenous. ${ }^{23}$ Furthermore, it is difficult to test for endogeneity by using either the Heckman method or an instrumental variable. In the first case, the inability to distinguish between the (a) and (b) groups prohibits the derivation of the appropriate Inverse Mills ratio (see Appendix A) and in the second case we would need a variable which is strongly correlated to caring but independent of the wage rate.

Thus, while we are unable to estimate a more general allocation-of-time model that controls for the possibility that informal care responsibilities are exogenously determined, there is the possibility of bias in our results. However, it is difficult to believe that for women anyway informal care is any more endogenous than child care and yet child care is generally treated as exogenous in labour supply models. Indeed, endogeneity is possibly more problematic in association with child care than with informal care. After all while contraception makes the decision to have children a genuine one, chronic illness in a close relative is something beyond the individual's control.

\footnotetext{
23 In the same way that using the wages of workers to estimate the offered wages of non-workers without allowing for self-selection leads to bias (because the decision to work is not exogenous). However, excluding informal care variables from the earnings equation allows for the possibility that informal care and earnings are jointly determined as in this case the initial estimate of the wage equation, excluding informal care variables, is effectively the reduced form earnings equation.
} 


\section{Summary and policy implications}

A comparison of male and female working age carers in the GHS data shows that not only are carers more likely to be women but that female carers care for longer hours and are more likely to be main carers than men. Nevertheless, more than $10 \%$ of men are carers and over a third of these men are sole main carers for some dependent. Furthermore, when men do undertake heavy caring commitments they seem just as willing to 'suffer' labour market losses as women. However, there are some differences in the nature of the losses suffered by male and female carers.

Econometric analysis of the GHS data confirms that the use of informal care to support the chronic sick and elderly in the community is costly for men as well as women. Both forego significant earnings because they are less likely to be in paid employment and when they are working they earn less than equally qualified non-carers. The direct earnings reduction increases with the degree of caring commitment and is greater for working men. One possible explanation for the relatively lower earnings of male carers is that the demands of informal care restrict their hours of employment to those consistent with periods when respite care is available. Their job opportunities will therefore be limited and those with more flexible hours are traditionally located in female labour markets where average earnings are lower. According to this line of reasoning, the earnings loss experienced by male carers depends on the gender wage gap and therefore these men would benefit from a relative improvement in female pay.

In contrast, the total effect on male participation is less than for females, at most reducing the probability of working by $12.9 \%$ (for male carers committed to at least $10 \mathrm{~h}$ of informal care per week). The comparable reduction in female labour market participation is a little over $27 \%$ and for some female carers with dependents in receipt of ATTAL it is higher still. Our results also suggest that the negative relationship between the probability of male employment and informal care is attributable solely to the negative indirect earnings effect; because carers earn less and earnings and employment participation are positively related, informal carers are less likely to be working. However, we found that for female carers caring for more than $10 \mathrm{~h}$ a week and those caring for a dependent in receipt of ATTAL there was an additional direct effect on participation such that they were significantly less likely to be in paid employment. These results are consistent with the traditionally weaker attachment of females to the labour force and might also suggest that for male carers the income effects of informal care are relatively more important.

The lack of a direct negative influence on male participation of either informal care responsibilities or the payment of informal care related benefits suggests that on the whole male carers do not willingly give up paid work even when caring for someone who is highly dependent. $^{24}$ This is true even though, or perhaps because, male carers earn significantly less than male non-carers. As a result, most male carers (and a significant number of female carers) are trying to combine full time work with their caring commitments. For these carers policies directed to respite care, carer-friendly employment practices and additional (non-means tested) financial support would be of particular benefit. The UK government

\footnotetext{
${ }^{24}$ It is not surprising that the payment of informal care related benefits do not give men an incentive to give up paid work as ATTAL and ICA are paid at a rate that is less than $1 \%$ of average male earnings in the sample.
} 
acknowledges the special needs of working carers and action on all three of these fronts is being considered to varying degrees. The national strategy for carers (Department of Health, 1999) outlines a clear business case for carer-friendly employment policies and the government has responded by offering unpaid leave for family emergencies. In 1999, £140 million over 3 years was set aside to improve the provision of respite care, i.e. services which typically allow carers occasional holidays, weekends off or an evening out. New powers have been given to local authorities to make direct cash payments to people who need care to pay for home care, day care or occasional short stays in residential or nursing homes. Although such payments are not made to carers they may enable respite for carers and may also in some cases allow dependents to assist their carers financially. The government has also proposed raising the means tested payments made directly to carers (by $£ 50$ a week in today's terms by 2050) and has introduced an entitlement to a second pension (Department of Health, 1999). Although such measures do not directly address the special needs of working carers the government has stated that financial support for working carers is to be kept under review (Department of Health, 1999). While such a commitment is welcome there is nothing to indicate any concrete intention to extend the current limited provisions. $^{25}$

The implementation of the kinds of polices outlined here give men as well as women a greater incentive to undertake care in the community. However, polices aimed specifically at working carers should give a particular incentive to men to undertake care. Men are a potential but still relatively under-utilised source of informal care and at a time when population ageing is making for increasing numbers requiring care, policy measures aimed at maintaining the supply of informal care need to be directed at men as well as women.

\section{Appendix A. Econometric model}

The wage equation is estimated in semi-log form ${ }^{26}$ and the offered market wage rate is assumed to be determined by the individual's human capital (following Mincer, 1974), derived from their level of skill, indicated by the highest educational and professional qualification obtained (EDUC), and their potential work experience, proxied by years since leaving full time education (YRSOUT and YRSOUTSQ). Temporary labour market disruptions due to childbirths are additionally allowed for in the female wage equations by a including set of dichotomous variables indicating the number of children to which the sample member has given birth (CHBORN1-CHBORN5+). ${ }^{27}$ Average earnings also vary locally and this is allowed for by a set of dichotomous variables indicating regions of residence (REGION). Informal care commitments can be allowed for by including a set of informal care indicators

\footnotetext{
25 The situation for working carers in the UK contrasts unfavourably with that in countries such as Canada where a tax credit for carers has been introduced.

26 This is the standard approach in labour economics because of the evidence that earnings are log-normally distributed (see, for example, Sapsford and Tzannatos, 1993, p.85).

27 In this study, we have tried to include the same variables in the male and female wage and participation equations but with the CHBORN variables this was clearly not possible. However, child care responsibilities are allowed for in both the male and female participation equations and therefore child care variables are included in the initial probit estimation required to estimate Heckman's $\lambda$ (see below).
} 
(INFCARE ${ }_{1}$ ). Thus, the wage equation to be estimated is of the form:

$$
\begin{aligned}
\ln \text { Wage }= & \alpha_{0}+\alpha_{1} \times \text { EDUC }+\alpha_{2} \times \text { YRSOUT }+\alpha_{3} \times \text { YRSOUTSQ }+\alpha_{4} \\
& \times \text { CHBORN }+\alpha_{5} \times \mathrm{INFCARE}_{1}+\alpha_{6} \times \mathrm{REGION}+\alpha_{7} \lambda+u_{1}
\end{aligned}
$$

where $\ln$ WAGE is the $\log$ of the offered market wage rate; $\lambda$ is the Inverse Mills ratio included (following Heckman, 1976) to counter for bias associated with a self-selected sample of labour market participants, ${ }^{28}$ and $u_{1}$ is the error term. ${ }^{29}$ We initially estimate Eq. (1) without including indicators of informal care to obtain the results in Table 4 and then subsequently include indicators of informal care in the calculation of WAGEFIT to obtain the results in Tables 5 and 6.

The employment participation equation is derived from the standard neo-classical incomeleisure choice model in which the individual's labour supply is assumed to result from a utility maximising choice, given the wage rate they can earn and any non-wage income available. The estimated labour market supply equation is given below, where WORK is a dichotomous variable representing the employment participation ${ }^{30}$ decision, taking the unit value when the individual works some positive number of hours:

$$
\begin{aligned}
\mathrm{WORK}= & \beta_{0}+\beta_{1} \times \mathrm{WAGEFIT}+\beta_{2} \times \mathrm{OTHINCO}+\beta_{3} \times \mathrm{OTHINCH}+\beta_{4} \\
& \times \mathrm{AGE}+\beta_{5} \times \mathrm{CHCARE}+\beta_{6} \times \mathrm{INFCARE}_{2}+\beta_{7} \times \mathrm{REGION}+u_{2}
\end{aligned}
$$

where OTHINCO and OTHINCH represent the individual's own non-wage income and other household income, respectively. ${ }^{31}$ CHCARE is a set of childcare indicators included

\footnotetext{
${ }^{28}$ Although, as stated, the estimated wage is an offered or market wage the Heckman method takes into account the reservation wage effect via $\lambda$ as it is the sign of the difference between a person's offered wage and their reservation wage that determines whether they select into paid work (see Greene, 1993, p. 708). However, we should note that recent research has shown that the parameter estimates from the selection model are sensitive to the assumption of normality which calls into question the generality of the model (Greene, 1993, p. 714). Greene (ibid) also refers to some alternative approaches to the selection problem based on robust and non-parametric methods that have greater generality but are limited in other ways. He concludes that the issue remains unsettled but that 'the empirical literature on the subject continues to be dominated by Heckman's original model built around the joint normal distribution'.

${ }^{29}$ An anonymous referee has pointed out that the possibility of discontinuity of the labour supply contract is only partially addressed by using an hourly wage measure. Including a dummy variable for part time status might help in this respect however this is not possible using the Heckman method as the determining variables in the reduced form probability of employment equation formulated to obtain the Inverse Mills ratio must be ones that can be measured for workers and non-workers alike. Furthermore, the predicted wage needs to be estimated for non-workers as well as workers and therefore the same restrictions on the independent variables apply. We did however estimate separate hours of work equations, but in all cases and for both the male and female samples, the influence of informal care responsibilities on hours of work is insignificant. We have also estimated full time participation equations with similar results. In the interests of brevity, these results are not reported but are available from the authors.

${ }^{30}$ Strictly speaking WORK indicates employment status rather than participation as the unemployed who are actively seeking work are clearly not working but are generally categorised as labour market participants. If WORK $=1$ then hours of work are positive.

31 These variables were taken directly from the GHS as ONS pre-constructed data. Although the GHS collects information on every member of each sample household, the data is made available to researchers via the ESRC Data Archive as 'organised' by the ONS. It is accessible either as a set of household files or as a set of individual
} 
in both the male and female estimations as the decision to take on paid work is likely to be influenced by current child care responsibilities including responsibility for step children etc. These responsibilities are proxied by a set of dichotomous variables indicating the age of the youngest dependent child in the family of the sample member (CHILD $<2$, CHILD2-4, CHILD5-10, CHILD11-16). As the CHBORN and CHILD variables are likely to be correlated they are not included together in any of the estimated equations. AGE is included to control for cohort-related attitudes towards employment and family responsibilities. INFCARE 2 is a set of informal care indicators that may differ from INFCARE . $_{\text {. }}$

The model is estimated in the standard way. The reduced form probability of employment equation is derived by substituting Eq. (1) into Eq. (2) and estimated by maximum likelihood methods; the resulting estimates are used to predict the value of Heckman's $\lambda$ for each sample member. The wage Eq. (1) is then estimated by OLS for the sub-sample of labour market participants. The structural form employment participation Eq. (2) is estimated in probit form across the sample as a whole with WAGEFIT, the log wage rate predicted from the estimated Eq. (1). In each case, the wage and participation equations are estimated separately for the male and female samples.

\section{Appendix B. Definition of variables}

\begin{tabular}{|c|c|}
\hline Variable & Definition \\
\hline ln WAGE & log of gross hourly wage rate $(£)$ \\
\hline WORK & $\begin{array}{l}\text { Dichotomous variable taking the unit value where sample } \\
\text { member is in paid employment }\end{array}$ \\
\hline CARE $<10 \mathrm{HRS}$ & $\begin{array}{l}\text { Dichotomous variable taking the unit value where the } \\
\text { sample member is an informal carer for whom the usual } \\
\text { amount of time spent on caring is less than } 10 \mathrm{~h} \text { per week }\end{array}$ \\
\hline $\mathrm{CARE} \geq 10 \mathrm{HRS}$ & $\begin{array}{l}\text { Dichotomous variable taking the unit value where the } \\
\text { sample member is an informal carer for whom the usual } \\
\text { amount of time spent on caring is at least } 10 \mathrm{~h} \text { per week }\end{array}$ \\
\hline MAIN CARER IN & $\begin{array}{l}\text { Dichotomous variable taking the unit value where the } \\
\text { sample member is a main carer for a dependant who shares } \\
\text { his or her household }\end{array}$ \\
\hline MAIN CARER OUT & $\begin{array}{l}\text { Dichotomous variable taking the unit value where the } \\
\text { sample member is a main carer for a dependant who does } \\
\text { not share his or her household }\end{array}$ \\
\hline
\end{tabular}

files. We use individual level data as our empirical model estimates individual labour supply. The record for each sample member contains their particular responses to the 'individual' questionnaire plus, as attached by the ONS, some of the information from the 'household' questionnaire and some data derived from the responses of other household members to their 'individual' questionnaires. The household income variable is a constructed variable in this sense. Given the well known difficulties associated with the derivation and calculation of unearned income measures the use of a measure constructed by the originators of the data seems the least problematic approach. However, as pointed out by an anonymous referee the disadvantage of using such a measure is that it cannot be broken down into components. 
Appendix B (Continued)

\begin{tabular}{|c|c|}
\hline Variable & Definition \\
\hline NMAIN CARER IN & $\begin{array}{l}\text { Dichotomous variable taking the unit value where the } \\
\text { sample member is a carer but not a main carer for a } \\
\text { dependant who shares his or her household }\end{array}$ \\
\hline NMAIN CARER OUT & $\begin{array}{l}\text { Dichotomous variable taking the unit value where the } \\
\text { sample member is a carer but not a main carer for a } \\
\text { dependant who does not share his or her household }\end{array}$ \\
\hline DEPATTAL & $\begin{array}{l}\text { Dichotomous variable taking the unit value where the } \\
\text { sample member is an informal carer for a dependent who } \\
\text { receives Attendance Allowance. The sample member may } \\
\text { also be claiming Invalid Care Allowance }\end{array}$ \\
\hline WAGEFIT & Predicted log of gross hourly wage rate $(\mathfrak{E})$ \\
\hline OTHINCO & $\begin{array}{l}\text { Weekly gross own income from sources other than earnings } \\
\text { (£) }\end{array}$ \\
\hline OTHINCH & Weekly gross income of other household members $(\mathfrak{f})$ \\
\hline AGE & Age of sample member \\
\hline YRSOUT & Years since leaving full time education \\
\hline YRSOUTSQ & The square of YRSOUT \\
\hline EDLEVA & $\begin{array}{l}\text { Dichotomous variable taking the unit value if the highest } \\
\text { educational qualification of the sample member is a higher } \\
\text { degree }\end{array}$ \\
\hline EDLEVB & $\begin{array}{l}\text { Dichotomous variable taking the unit value if the highest } \\
\text { educational qualification of the sample member is a first } \\
\text { degree or equivalent diploma }\end{array}$ \\
\hline EDLEVC & $\begin{array}{l}\text { Dichotomous variable taking the unit value if the highest } \\
\text { educational qualification of the sample member is an HNC; } \\
\text { Btec; City and Guilds (Part III): nursing qualification; } \\
\text { teaching qualification, or equivalent }\end{array}$ \\
\hline EDLEVD & $\begin{array}{l}\text { Dichotomous variable taking the unit value if the highest } \\
\text { educational qualification of the sample member is a GCE A } \\
\text { level; CGE O level; CSE; trade apprenticeship; City and } \\
\text { Guilds (Part I or II); clerical and commercial qualification; } \\
\text { or equivalent }\end{array}$ \\
\hline EDLEVF & $\begin{array}{l}\text { Dichotomous variable taking the unit value if the highest } \\
\text { educational qualification of the sample member is a foreign } \\
\text { qualification }\end{array}$ \\
\hline CHILD $<2$ & $\begin{array}{l}\text { Dichotomous variable taking the unit value where the } \\
\text { youngest child in the family of the sample member is less } \\
\text { than } 2 \text { years old }\end{array}$ \\
\hline CHILD2-4 & $\begin{array}{l}\text { Dichotomous variable taking the unit value where the } \\
\text { youngest child in the family of the sample member is } \\
\text { between } 2 \text { and } 4 \text { years of age }\end{array}$ \\
\hline
\end{tabular}




\section{Appendix B (Continued)}

\begin{tabular}{ll}
\hline Variable & Definition \\
\hline CHILD5-10 & $\begin{array}{l}\text { Dichotomous variable taking the unit value where the } \\
\text { youngest child in the family of the sample member is } \\
\text { between } 5 \text { and } 10 \text { years of age } \\
\text { Dichotomous variable taking the unit value where the } \\
\text { youngest child in the family of the sample member is } \\
\text { between } 11 \text { and } 16 \text { years of age }\end{array}$ \\
CHILD BORN DUMMIES & $\begin{array}{l}\text { Dichotomous variables taking the unit value where the } \\
\text { sample member has given birth to } i \text { children }(i=1, \ldots, 4, \\
5 \text { or more) }\end{array}$ \\
REGIONAL DUMMIES & $\begin{array}{l}\text { Dichotomous variables taking the unit value where the } \\
\text { sample member lives in } 1 \text { of } 22 \text { regions in the Britain }\end{array}$ \\
Heckman's sample selection term
\end{tabular}

\section{References}

Carmichael, F., Charles, S., 1997. Informal care and female labour supply some results from the 1990 GHS'. Aberystwyth Economic Research Papers, 97-15.

Carmichael, F., Charles, S., 1998. The labour market costs of community care. Journal of Health Economics 17 (6), 645-795.

Department of Health, 1989. Caring for people; community care in the next decade and beyond, Cm. 849. HMSO, London.

Department of Health, 1998. Modernising social services, Cm. 4169. HMSO, London.

Department of Health, 1999. Caring about carers: a national strategy for carers, http://www.doh.gov.uk/carers.htm. Greene, W.H., 1993. Econometric Analysis. Macmillan, New York.

Heckman, J.J., 1976. The common structure of statistical models of truncated, sample selection and limited dependent variables, and a simple estimator for such models. Annals of Economic and Social Measurement 5, 475-492.

Mincer, J., 1974. Schooling Experience Ad Earnings. National Bureau of Economic Research, New York.

Parker, G., 1993. With this Body, Caring and Disability in Marriage. Open University Press, Buckingham.

Rowlands, O., Parker, G., 1998. Informal carers: an independent study carried out by the Office for National Statistics on behalf of the Department of Health as part of the 1995 General Household Survey. HMSO, London.

Sapsford, D., Tzannatos, Z., 1993. The Economics of the Labour Market. Macmillan, Basingstoke.

Twigg, J., Atkin, K., 1994. Carers Perceived Policy and Practice in Informal Care. Open University Press, Buckingham. 